\title{
Deep brain stimulation for monogenic Parkinson's disease: a systematic review
}

\author{
Tomi Kuusimäki ${ }^{1,2}$ (1) $\cdot$ Jaana Korpela ${ }^{1,2} \cdot$ Eero Pekkonen $^{3,4} \cdot$ Mika H. Martikainen $^{1,2} \cdot$ Angelo Antonini $^{5}$. \\ Valtteri Kaasinen $^{1,2}$
}

Received: 11 November 2018 / Revised: 29 December 2018 / Accepted: 2 January 2019 / Published online: 18 January 2019

(c) The Author(s) 2019

\begin{abstract}
Deep brain stimulation (DBS) is an effective treatment for Parkinson's disease (PD) patients with motor fluctuations and dyskinesias. The key DBS efficacy studies were performed in PD patients with unknown genotypes; however, given the estimated monogenic mutation prevalence of approximately 5-10\%, most commonly LRRK2, PRKN, PINK1 and SNCA, and risk-increasing genetic factors such as $G B A$, proper characterization is becoming increasingly relevant. We performed a systematic review of 46 studies that reported DBS effects in 221 genetic PD patients. The results suggest that monogenic PD patients have variable DBS benefit depending on the mutated gene. Outcome appears excellent in patients with the most common LRRK2 mutation, p.G2019S, and good in patients with PRKN mutations but poor in patients with the more rare LRRK2 p.R1441G mutation. The overall benefit of DBS in SNCA, GBA and LRRK2 p.T2031S mutations may be compromised due to rapid progression of cognitive and neuropsychiatric symptoms. In the presence of other mutations, the motor changes in DBS-treated monogenic PD patients appear comparable to those of the general PD population.
\end{abstract}

Keywords Parkinson's disease $\cdot$ Monogenic $\cdot$ Genetic $\cdot$ Deep brain stimulation

\section{Introduction}

Deep brain stimulation (DBS) provides symptomatic motor benefit for patients with advanced Parkinson's disease (PD) [1-4]. The benefit of symptom control through DBS surpasses that of optimal medical treatment in patients with

Electronic supplementary material The online version of this article (https://doi.org/10.1007/s00415-019-09181-8) contains supplementary material, which is available to authorized users.

* Tomi Kuusimäki tomi.kuusimaki@utu.fi

1 Division of Clinical Neurosciences, Turku University Hospital, Hämeentie 11, POB 52, 20521 Turku, Finland

2 Department of Neurology, University of Turku, Turku, Finland

3 Department of Neurology, Helsinki University Hospital, Helsinki, Finland

4 Department of Clinical Neurosciences (Neurology), University of Helsinki, Helsinki, Finland

5 Department of Neurosciences, University of Padua, Padua, Italy motor fluctuations and dyskinesias, and it is a relatively safe treatment option for motor complications of idiopathic PD [1-5]. DBS is often performed in relatively early-onset PD, a population in which it has been estimated that at least 5-10\% of cases are not sporadic, but may carry genetic mutations $[6,7]$. Genetic cases often are phenotypically different compared to sporadic patients, and this factor may influence clinical outcome $[6,8]$.

Though DBS has demonstrated efficacy, randomized studies have been performed in PD patients without genetic characterization raising questions of suitability of various monogenic forms and their relevance in DBS outcome. It is known that medication effects may vary between different mutations. For example, patients with $P R K N$ mutations generally are particularly prone to levodopa-induced dyskinesias, whereas patients with LRRK2 mutations tend to show a normal sustained benefit for levodopa [8-11]. The effects of other antiparkinsonian drugs, such as rasagiline, may also be modulated by the genotype [12]. Given the variability in medication effects, it is conceivable that there are also differences in the treatment response to DBS in advanced monogenic PD. There are several case reports and small case series of DBS outcomes in patients with genetic 
PD, but due to a lack of information synthesis, we performed a systematic review on the effects of DBS in genetic PD.

\section{Methods}

\section{Search strategy}

The Preferred Reporting Items for Systematic Reviews and Meta-Analyses (PRISMA) statement was followed [13]. We performed a PubMed search from inception to June 26, 2018 with keywords "deep brain stimulation or DBS", "Parkinson's or Parkinson or Parkinsonism" and "genetic or gene or GBA or PRKN or PARKIN or LRRK2 or SNCA or PINK1 or VPS35 or DJ-1 or UCHL1 or GIGYF2 or HTRA2 or
TMEM230 or CHCHD2 or RIC3 or ATP13A2 or PLA2G6 or FBX07 or SYNJ1 or VPS13C or DNAJC6". All original English language articles concerning genetic PD patients treated with DBS were included. Animal studies and review articles were excluded.

The initial search identified 220 articles, and we included an additional 16 relevant studies found in the manual search of reference lists (Fig. 1). All abstracts of these studies were screened, and 184 studies were excluded in the first round (no monogenic PD patients or not treated with DBS $n=64$, review or commentary article $n=92$, animal study $n=28$ ). The remaining 52 studies were assessed fully for eligibility and six more studies were excluded in the second round (genetic test negative $n=2$, no genetic testing $n=1$, review or commentary article $n=3$ ). Finally, 46 studies of these
Fig. 1 Flow chart of study inclusion and exclusion

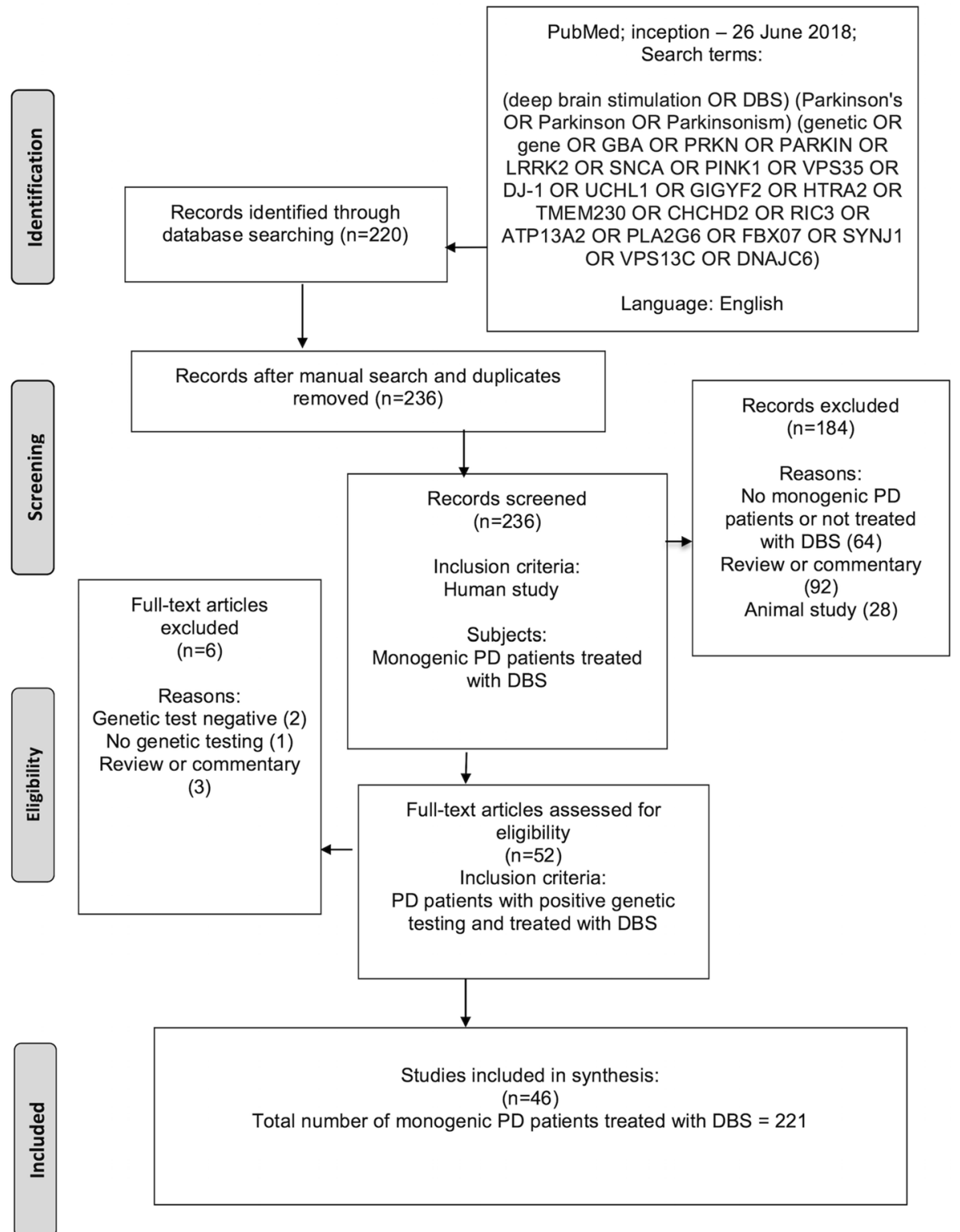


236 studies met all selection criteria and were included in the systematic review (Table 1). A summary of the included studies is presented in Table 2. The included studies reported 221 genetic PD patients who were treated with DBS. However, two studies reported partially the same patients $[14$, $15]$.

\section{Specific aims}

This review of evidence aimed to systematically investigate DBS outcome in monogenic PD compared to the general PD population. The primary aim was to evaluate the motor benefit of the DBS operation in each monogenic PD type. An additional aim was to evaluate effects on non-motor symptoms, including possible cognitive and neuropsychiatric symptoms.

\section{Selection criteria}

Search terms and the PubMed search were planned by two authors (T.K. and V.K.). All titles and abstracts were reviewed by one investigator (T.K.). Studies were excluded if the title and/or abstract were not suitable for the aim of the review. Full texts were obtained for appropriate studies or if the relevance of an article was uncertain. The inclusion criteria for the selected studies were as follows: (1) a human study, (2) genetic PD patients treated with DBS, and (3) English language. The data extracted from each study were study year, first author's family name, number of patients, mutated gene, specific mutation, patient age at disease onset and DBS implantation, target nucleus of DBS, more specific lead positioning, pre- and postoperative UPDRS-III scores, follow-up time and outcome (Table 1). UPDRS-III scores of control cohort's (mutation non-carriers, NC) are also reported in Table 1 if the information was available. In the outcome evaluation, an improvement of $30 \%$ or more in the UPDRS-III motor score was considered to indicate favourable outcome; 20-30\%, moderate outcome; and $<20 \%$, poor/mild outcome [58-60].

\section{Quality control}

The quality of the included studies was evaluated according to the Newcastle-Ottawa Scale (NOS) [61]. NOS includes selection, comparability, and exposure or outcome. The scale ranged from 0 to 11 stars, with the highest rating representing the greatest quality. Six months or more was a limit for the adequate follow-up time. Pre- and postoperative evaluation was thought to be accomplished if the outcome was reported properly with percentage improvement of the UPDRS-III score or verbally. A total score of 0-3 was considered to indicate to poor quality; $4-7$, moderate quality; and $8-11$, good quality. The NOS total score is presented in
Table 1 and the scale is presented more accurately in Supplementary Table 1. A summary of the assessed quality of the studies is presented in Supplementary Table 2.

\section{Results}

A summary of the primary results is presented in Table 2 . Altogether, 46 studies and 221 monogenic PD patients treated with DBS were included in the systematic review (Table 1).

\section{LRRK2}

Seventeen studies $[9,15-30]$ reported 87 patients (target: subthalamic nucleus (STN) $n=79$, not available (NA) $n=8$ ). The outcome was reported in 73 patients (83.9\% of patients); with percentage improvement of the UPDRS-III score in 49 patients and verbally in 24 patients. The motor outcome was mostly favourable in patients with $L R R K 2$ mutation. Only five studies with ten patients reported poor/mild/moderate outcomes. Both patients with the p.T2031S (c.6091A > T) mutation $(n=2)$ developed neuropsychiatric problems 5-7 years after implantation. The outcome appeared poor in patients with p.R1441G (c.4321C > G) mutations whereas it appeared excellent in patients with p.G2019S (c.6055G > A) mutations.

\section{PRKN}

Eighteen studies [11, 15, 16, 19, 21, 31-43] reported 67 patients ( $\mathrm{STN} n=51$, globus pallidus interna (GPi) $n=5$, zona incerta $n=1$, NA $n=10$ ). The outcome was reported in 57 patients $(85.1 \%)$; UPDRS-III percentage improvement was reported in 45 patients and the outcome was described verbally in 12 patients. Fifty-one patients (76.1\%) had favourable long-term motor outcomes. Six patients in three different studies were reported to have modest or poor outcomes.

\section{GBA}

Five studies [14, 15, 19, 44, 45] reported 50 patients (STN $n=33$, GPi $n=4$, ventral intermediate nucleus (VIM) $n=1$, NA $n=12$ ). Samples partially consisted of same patients in two studies $[14,15]$. The outcome was reported in 30 patients $(60.0 \%)$; UPDRS-III percentage improvement in 28 patients and the outcome was described verbally in 2 patients. Eighteen patients were reported to have favourable, three patients moderate and nine patients poor long-term motor outcomes. One study reported better outcomes with STN-DBS and VIM-DBS than with GPi-DBS 


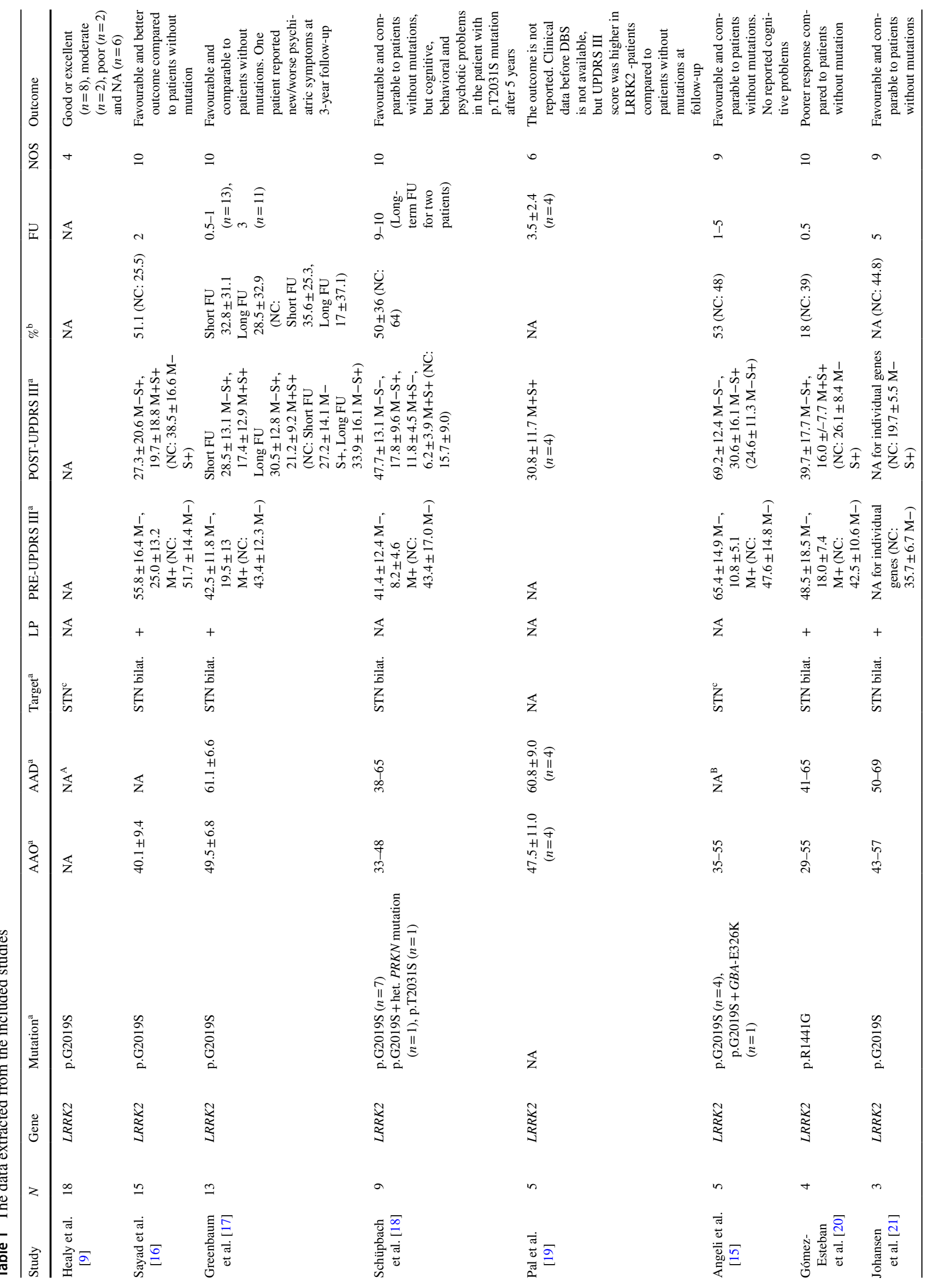




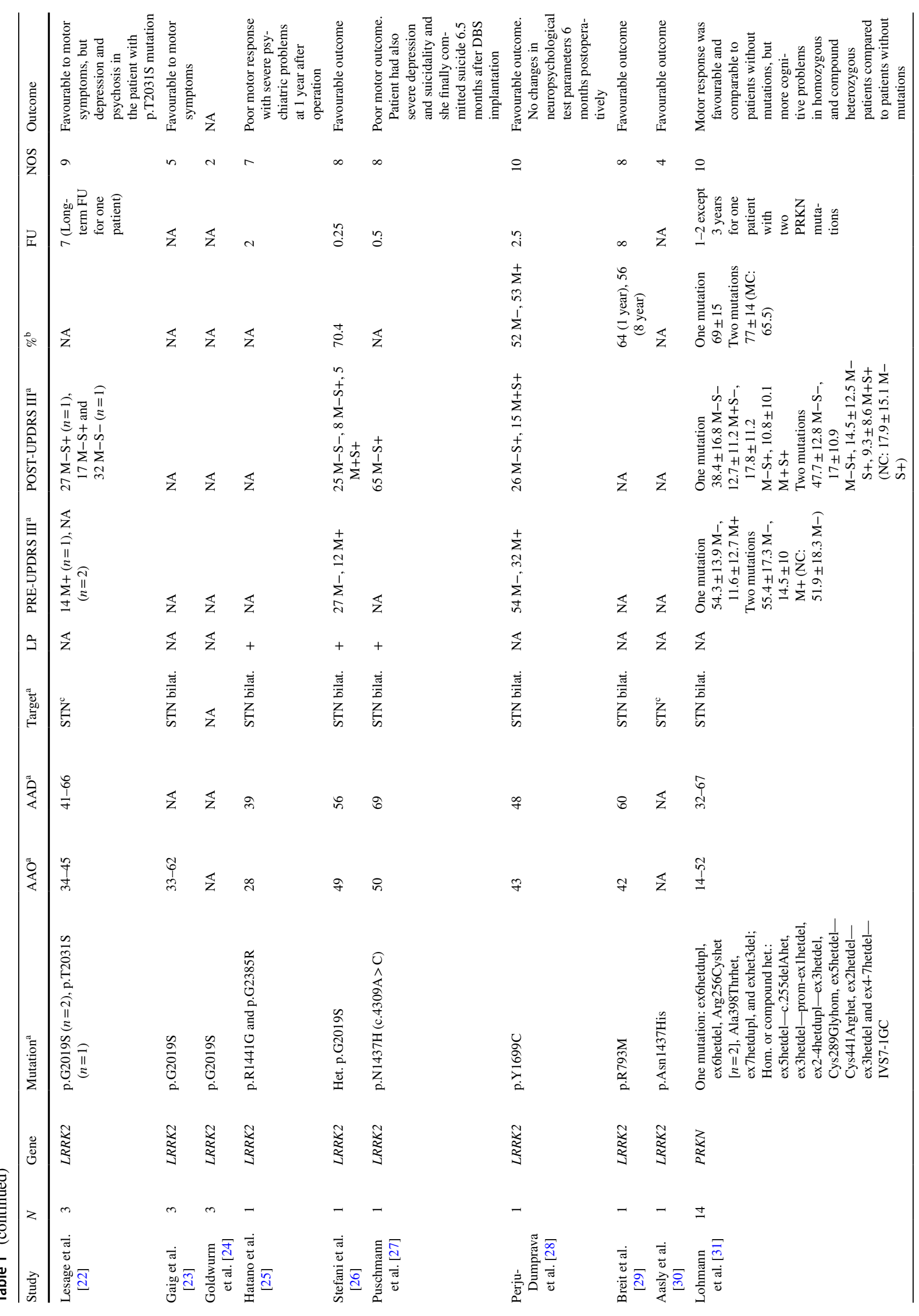


888

Journal of Neurology (2020) 267:883-897

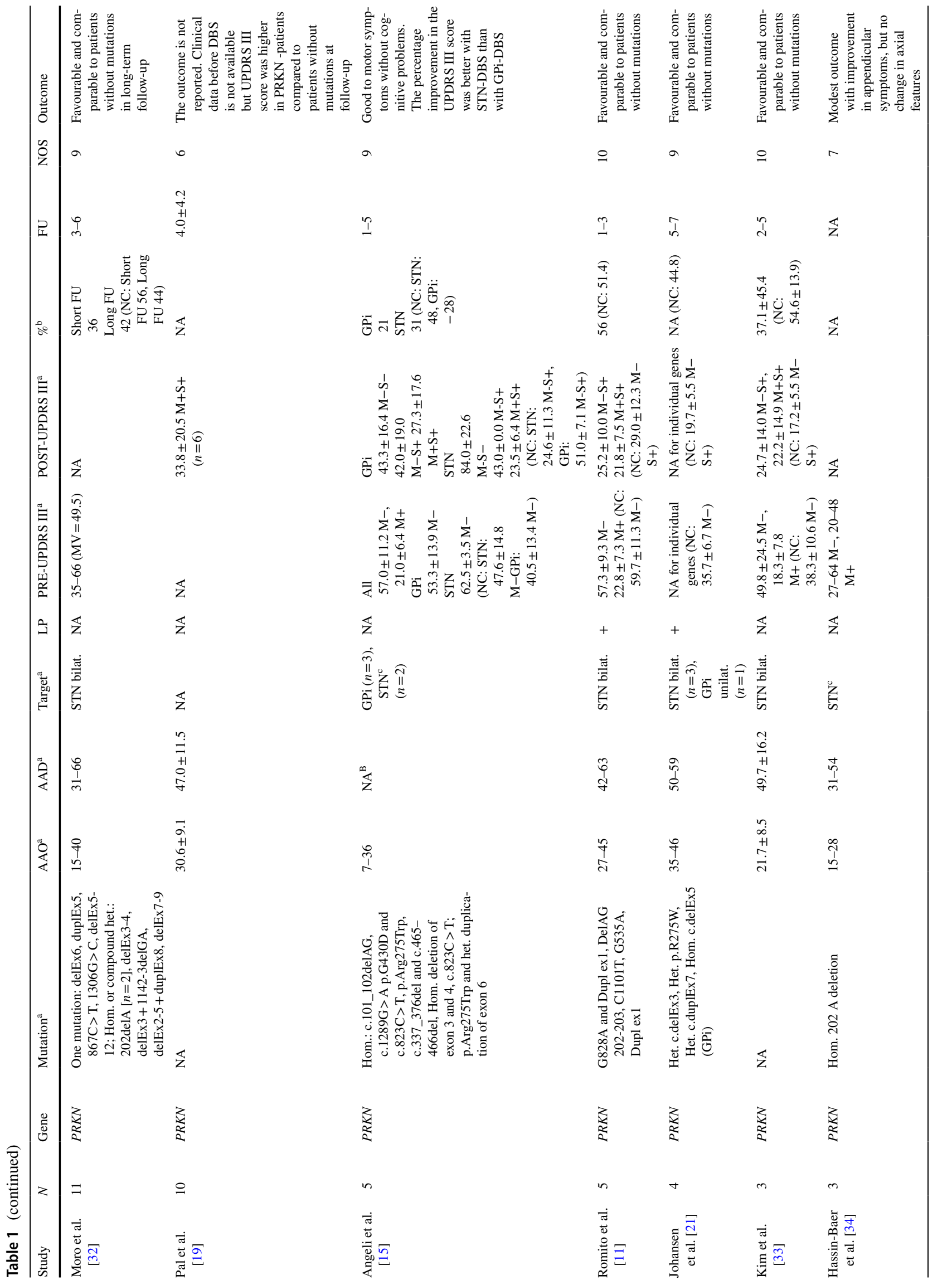

Springer 


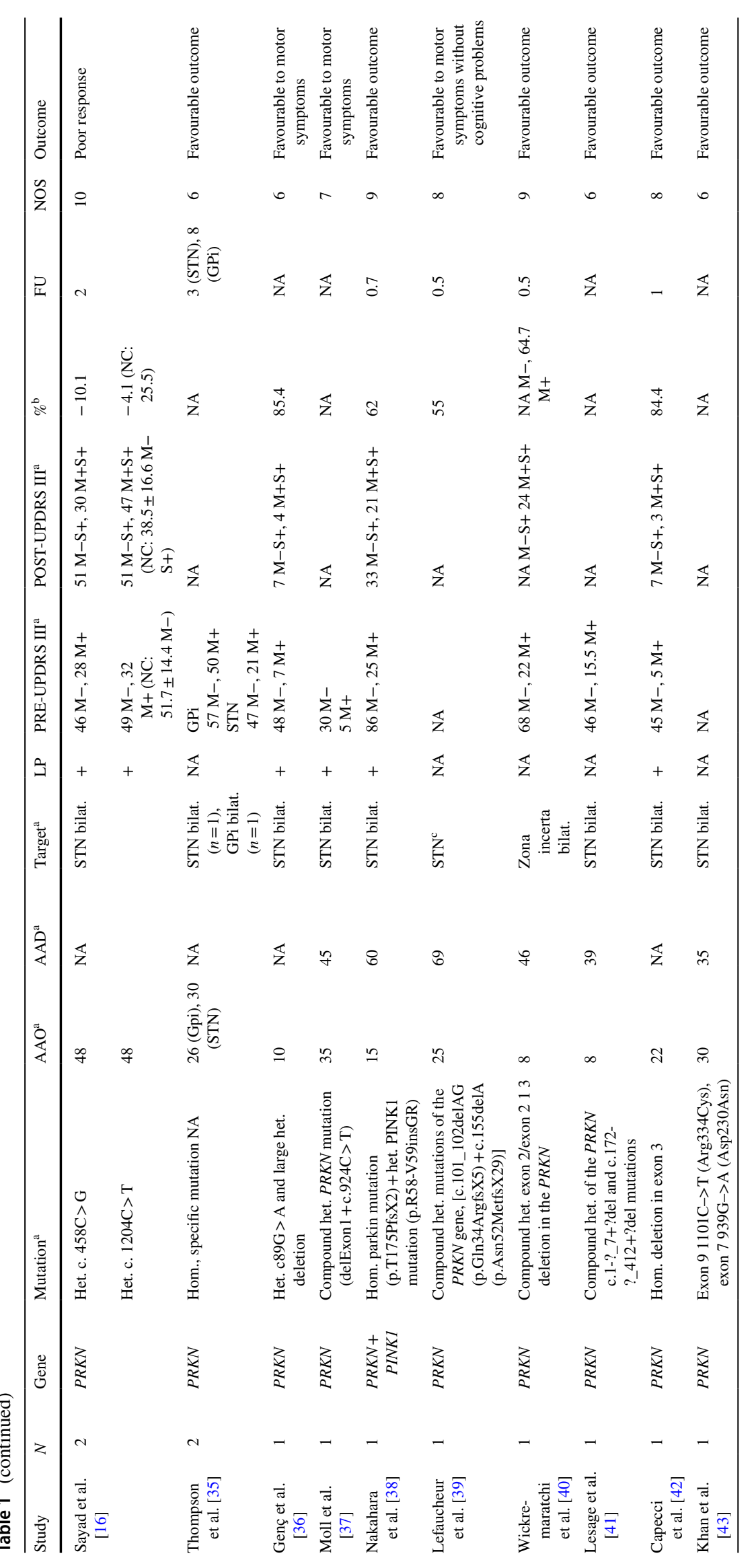




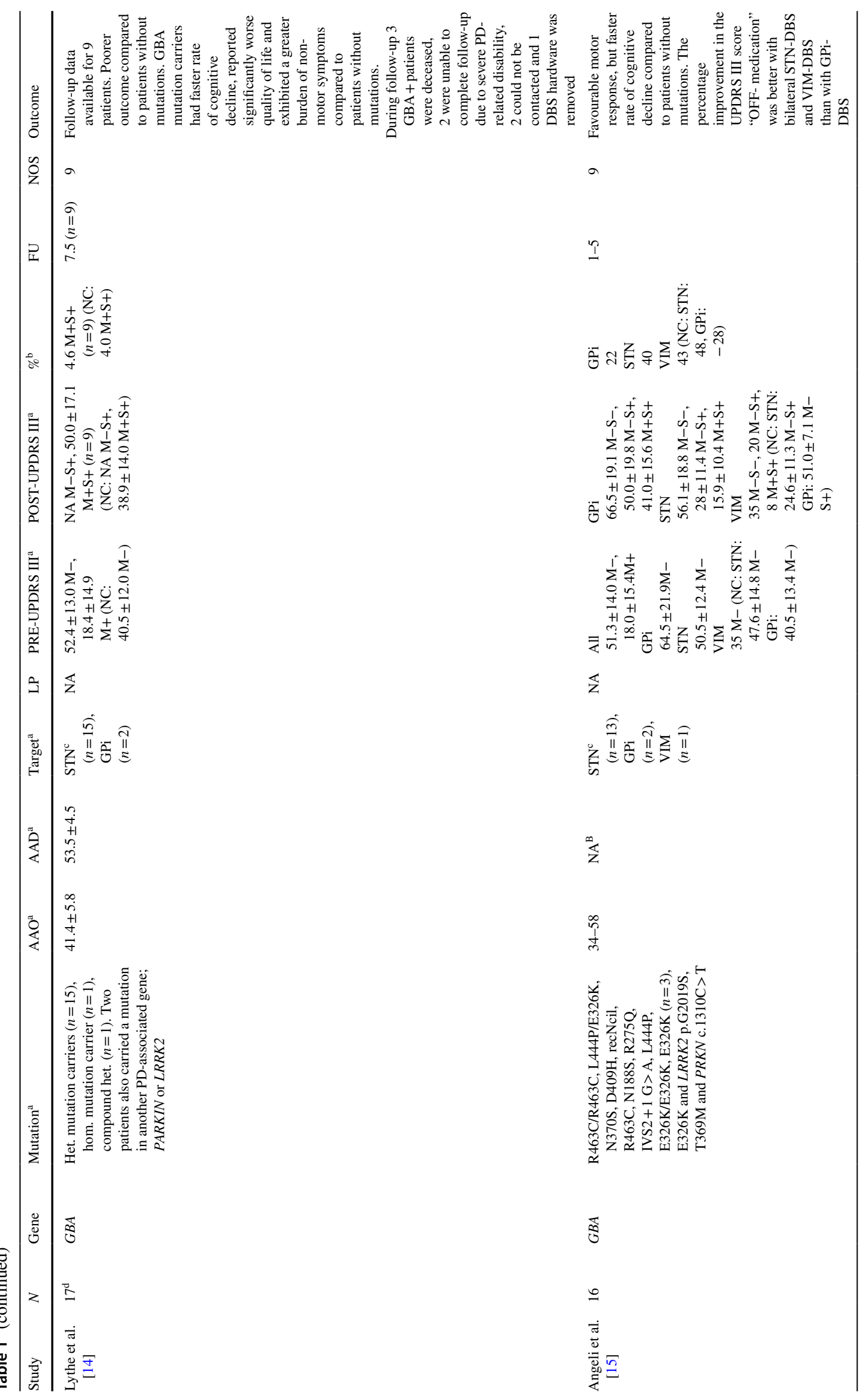




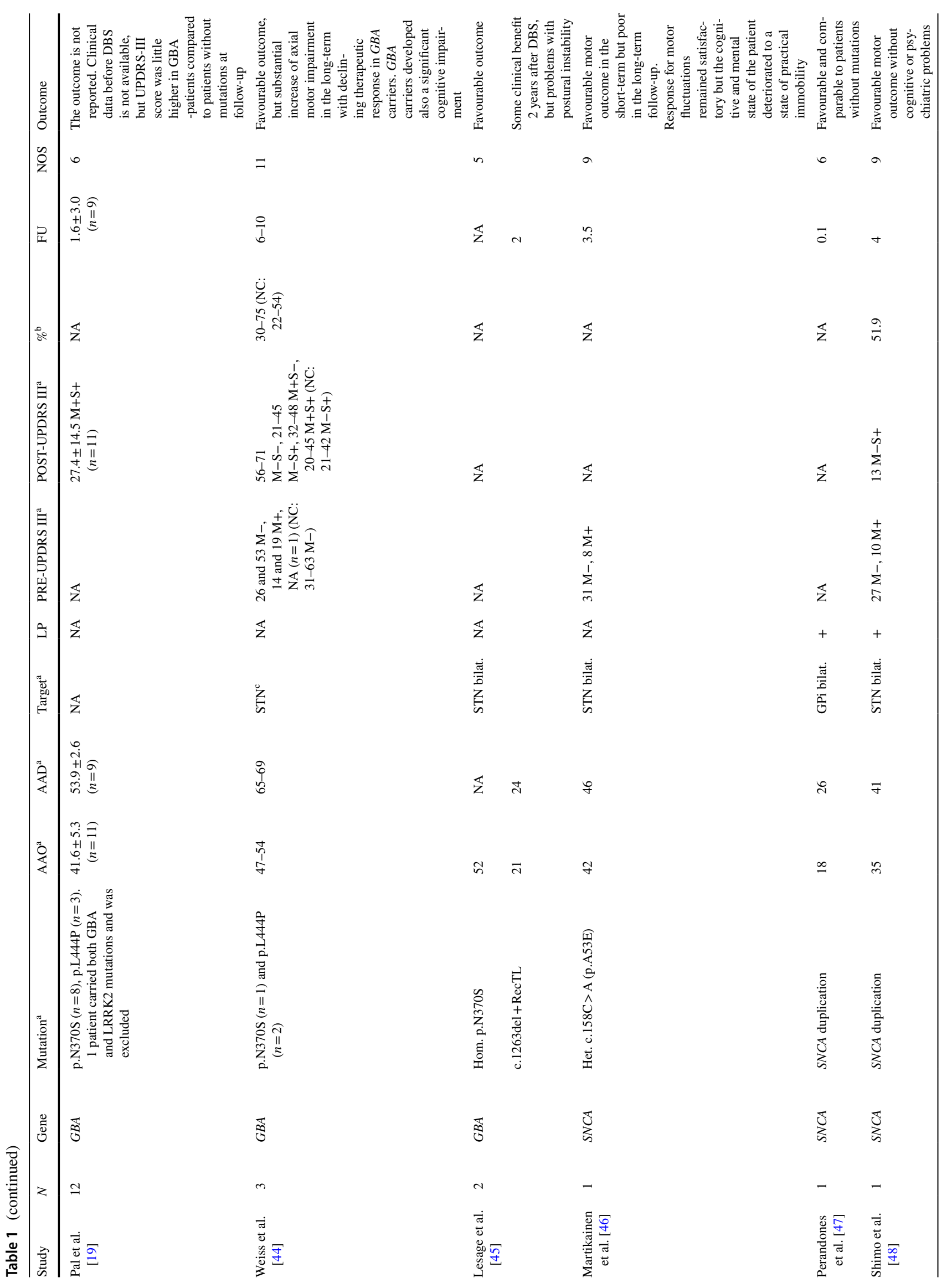




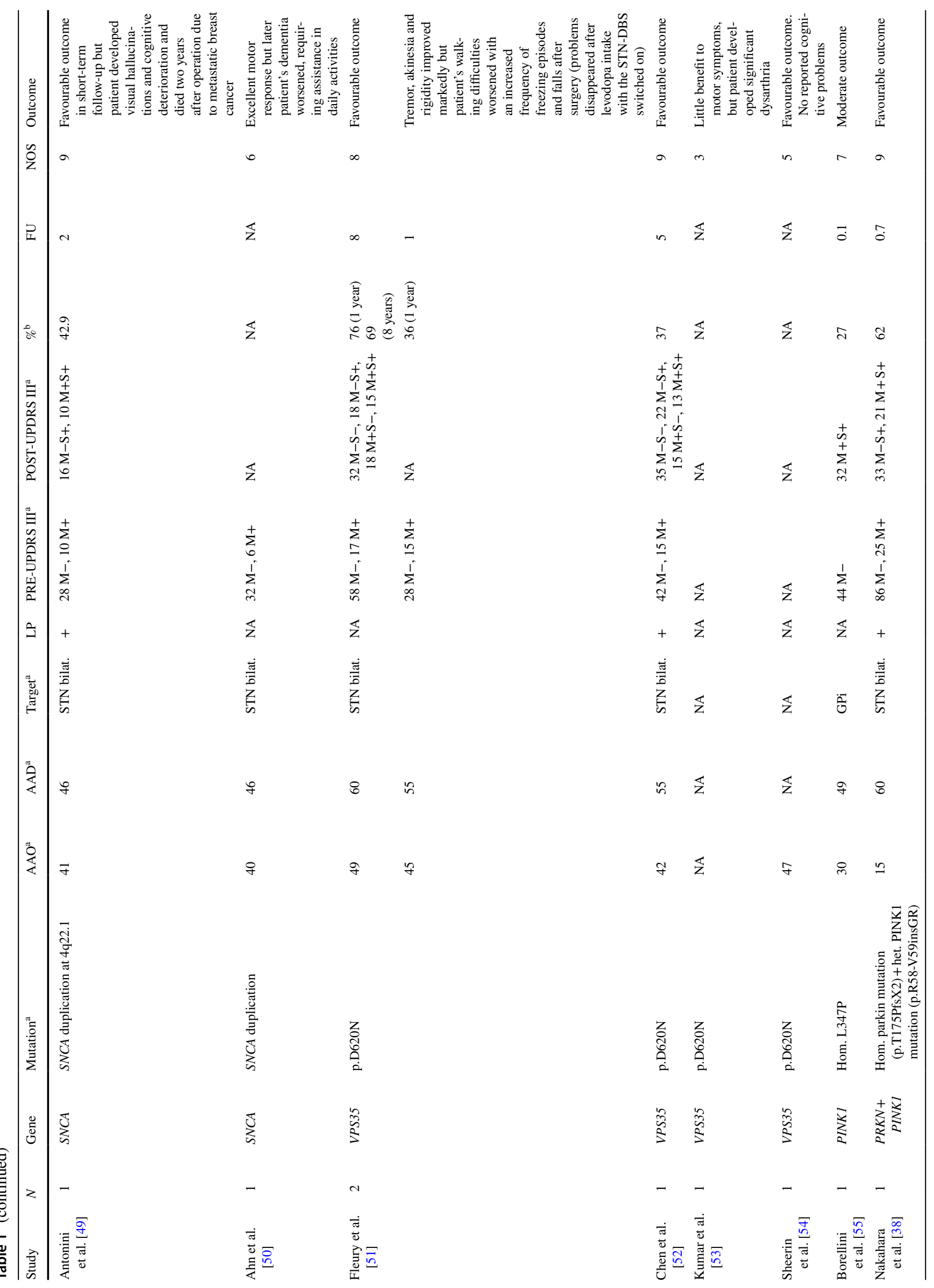




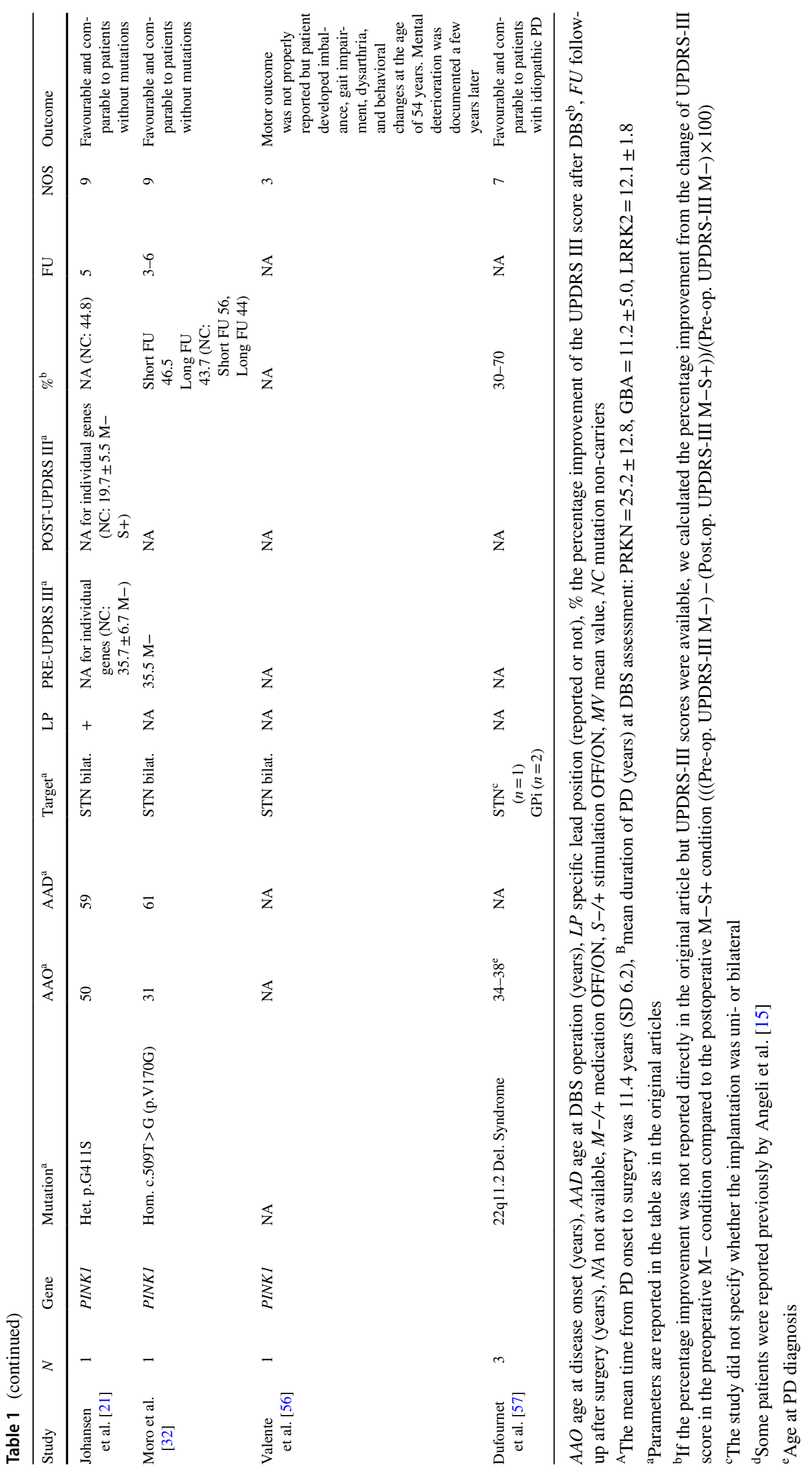


Table 2 Summary of key findings according to the mutated gene

\begin{tabular}{|c|c|c|c|c|}
\hline Gene & Studies $(n)$ & Patients $(n)$ & Target & Outcome \\
\hline LRRK2 & 17 & $87^{\mathrm{a}}$ & $\begin{array}{l}\text { STN: } n=79(90.8 \%) \\
\text { NA: } n=8(9.2 \%)\end{array}$ & $\begin{array}{l}\text { Mostly favourable motor outcome. Four studies with eight patients } \\
(9.2 \%) \text { reported poor motor outcomes and one study reported moder- } \\
\text { ate outcomes for two patients. Both patients with the } L R R K 2 \text { p.T2031S } \\
(\text { c. } 6091 \mathrm{~A}>\mathrm{T}) \text { mutation }(n=2) \text { developed neuropsychiatric problems } \\
5-7 \text { years after implantation. The outcome appears poor in patients with } \\
\text { LRRK2 p.R1441G (c. } 4321 \mathrm{C}>\mathrm{G}) \text { mutations }(n=5) \text {, whereas it appears } \\
\text { excellent in patients with } L R R K 2 \text { p.G2019S }(\mathrm{c} .6055 \mathrm{G}>\mathrm{A}) \text { mutations }\end{array}$ \\
\hline$P R K N$ & 18 & $67^{\mathrm{b}}$ & $\begin{array}{l}\text { STN: } n=51(76.1 \%) \\
\text { GPi: } n=5(7.5 \%) \\
\text { Zona incerta: } n=1(1.5 \%) \\
\text { NA: } n=10(14.9 \%)\end{array}$ & $\begin{array}{l}\text { Fifty-one patients }(76.1 \%) \text { had favourable long-term motor outcomes. Four } \\
\text { patients }(6.0 \%) \text { were reported to have modest outcome in two different } \\
\text { studies and one study with two patients }(3.0 \%) \text { reported poor benefit }\end{array}$ \\
\hline$G B A$ & 5 & $50^{\mathrm{c}}$ & $\begin{array}{l}\text { STN: } n=33(66.0 \%) \\
\text { GPi: } n=4(8.0 \%) \\
\text { VIM: } n=1(2.0 \%) \\
\text { NA: } n=12(24.0 \%)\end{array}$ & $\begin{array}{l}\text { Eighteen patients were reported to have favourable, three patients moderate } \\
\text { and } 9 \text { patients poor long-term motor outcomes. One study reported better } \\
\text { outcomes with STN-DBS and VIM-DBS than with GPi-DBS. GBA muta- } \\
\text { tion carriers developed cognitive impairment faster than patients without } \\
\text { mutations }\end{array}$ \\
\hline$S N C A$ & 5 & 5 & $\begin{array}{l}\text { STN: } n=4(80.0 \%) \\
\text { GPi: } n=1(20.0 \%)\end{array}$ & $\begin{array}{l}\text { Favourable motor outcome but three of five patients developed cognitive or } \\
\text { neuropsychiatric problems a few years after implantation }\end{array}$ \\
\hline VPS35 & 4 & 5 & $\begin{array}{l}\text { STN: } n=3(60.0 \%) \\
\text { NA: } n=2(40.0 \%)\end{array}$ & $\begin{array}{l}\text { Favourable motor outcome in four cases and minor motor benefit compli- } \\
\text { cated by dysarthria in one case }\end{array}$ \\
\hline PINK1 & 5 & $5^{\mathrm{b}}$ & $\begin{array}{l}\text { STN: } n=4(80.0 \%) \\
\text { GPi: } n=1(20.0 \%)\end{array}$ & Favourable motor outcome in three cases and moderate in one case \\
\hline $\begin{array}{l}\text { 22q11.2.Del. } \\
\text { Syndrome }\end{array}$ & 1 & 3 & $\begin{array}{l}\text { STN: } n=1(33.3 \%) \\
\text { GPi: } n=2(66.6 \%)\end{array}$ & Favourable motor outcome \\
\hline
\end{tabular}

STN subthalamic nucleus, GPi globus pallidus interna, VIM ventral intermediate nucleus, $N A$ not available

${ }^{a}$ One patient had also PRKN mutation and one had GBA mutation

${ }^{\mathrm{b}}$ One patient had both PRKN and PINK1 mutations

${ }^{\mathrm{c}}$ Two studies reported partially same patients, but it was not possible to separate individual patients that were reported twice. One patient had also LRRK2 mutation and one had PRKN mutation

[15]. GBA mutation carriers developed cognitive impairment faster than patients without mutations.

\section{SNCA}

Five patients were reported in five case reports [46-50] (STN $n=4$, GPi $n=1$ ). The motor outcome was favourable for all patients in the short-term but 3/5 patients developed cognitive and/or neuropsychiatric problems a few years after implantation. The percentage change in the UPDRS-III score was documented in two patients.

\section{VPS35}

Four studies [51-54] reported five patients ( $\operatorname{STN} n=3$, NA $n=2)$. Favourable motor outcome was reported in four cases and minor motor benefit complicated by dysarthria in one case. The percentage change in the UPDRS-III score was reported in three patients.

\section{PINK1}

Five case reports $[21,32,38,55,56]$ including one patient in each report (STN $n=4$, GPi $n=1$ ) were reported. Favourable motor outcome was observed in three patients and moderate outcome in one case. One patient developed imbalance, gait impairment, dysarthria, and behavioral changes after operation and mental deterioration was documented a few years later.

\section{Exclusion of poorer quality studies}

Unfortunately, many studies (Table 1) lacked important information as shown in the Supplementary Table 1. Poorer quality studies have tendency for bias; therefore, in the Supplementary Table 3, data are presented after exclusion of poorer quality studies such as studies lacking the information about DBS target, pre- and postoperative evaluation, adequate follow-up time or outcome information. Furthermore, as Lythe et al. [14] and Angeli et al. [15] reported partly the same patients, we tested the conclusions also when the smaller study was excluded. Nevertheless, after the 
exclusion of these studies, the results remained essentially the same (Supplementary Table 4).

\section{Discussion}

We report the following key findings: (1) DBS outcome appears excellent in patients with $L R R K 2$ p.G2019S (c.6055G > A) mutations, good in patients with $P R K N$ mutations and poor in patients with LRRK2 p.R $1441 \mathrm{G}$ (c. $4321 \mathrm{C}>\mathrm{G}$ ) mutations, (2) the overall benefit of DBS in SNCA, GBA and LRRK2 p.T2031S (c.6091A > T) mutations may be decreased due to rapid progression of cognitive and neuropsychiatric symptoms, and (3) in other mutations, the motor outcome in DBS-treated genetic PD patients appears generally comparable to that of sporadic PD patients.

A recent smaller review of 30 studies described the effects of DBS mainly in patients with $L R R K 2, P R K N$ and $G B A$ mutations [62]. In the present PRISMA-compliant systematic review of 46 studies and 221 patients, the most comprehensive data were available for patients with $L R R K 2$ and PRKN mutations. The combined evidence suggests that patients with $L R R K 2$ mutations generally have a good response to DBS, and patients with the most common LRRK2 mutation, the p.G2019S mutation [7], may even have better outcome than the general PD population. However, the reported $L R R K 2$ cases of p.R114G, p.T2031S and p.N1437H (c.4309A > C) mutation carriers appeared to have less favourable outcome. This interpretation is limited by the small number of reported DBS-treated cases of rarer $L R R K 2$ mutations. For the $P R K N$ mutations, the literature supports a view that patients with $P R K N$ mutations are optimal candidates for DBS.

Apart from the $L R R K 2$ and $P R K N$ genes, the published literature concerning individual monogenic mutations and DBS is less comprehensive and the data are clearly limited with respect to both the number of patients and duration of follow-up. The available data are limited to five DBStreated patients with VPS35 mutation, and the patients have shown favourable sustained motor outcome in $4 / 5$ cases. The available literature also suggests that most patients with mutations in $G B A$ tend to achieve favourable long-term motor outcome from STN-DBS. Despite good motor outcome, $G B A$ mutation carriers may develop cognitive impairment after DBS faster than patients without mutations. SNCA patients commonly develop cognitive and neuropsychiatric problems [8]. The literature supported a good motor outcome after DBS also in patients with SNCA mutations; however, 3/5 patients developed cognitive and neuropsychiatric problems a few years after DBS implantation. Indeed, the non-motor features of genetic PD may be a limiting factor in the overall benefit of DBS in some mutations, such as SNCA and LRRK2 p.T2031S. While the motor benefit from DBS may initially be clear, the rapid non-motor progression may lessen the sum value for the quality of life. A recent study in $S N C A$ A53T mutated rodents suggested that DBS may be neuroprotective [63]. Nonetheless, in human PD patients with SNCA mutations, the neuropsychiatric progression appears to be rapid despite DBS. The issue could be the level of damage at the time of implantation, and earlier DBS in these patients might possibly provide different outcomes.

Preoperative response to levodopa is the best single predictor of the postoperative outcome of DBS [64]. This indicator appears useful also in patients with monogenic mutations and the response was reported in practically all included studies. Another relevant predictor is the localization of DBS electrodes [65]. Unfortunately, there were studies, which did not report DBS targets and most studies lacked information about lead positioning. As the literature expands in the future, the effect of targets and lead positioning should be investigated in more detail. In most studies, STN was preferred over GPi as the target. Hence it remains ambiguous whether there are any relevant differences of clinical outcome between STN and GPi stimulation in monogenic PD. One study reported also a patient with VIM stimulation which is an unusual target for PD patients because VIM stimulation improves only tremor, not other PD symptoms $[66,67]$. Finally, it is important to note that the genetic status may have a positive as well as a negative influence on outcome of surgery and this issue should be taken into consideration in the interpretation of DBS studies. For example, the EARLYSTIM trial was performed with young-onset $\mathrm{PD}$ patients [5] and there could have been an overrepresentation of PRKN patients in the sample.

In conclusion, monogenic PD patients have variable DBS outcomes depending on the mutated gene. Most patients benefit from STN-DBS, at least in the short-term; however, the current evidence does not support or is questionable for DBS implantation for patients with p.T2031S or p.R114G mutations in the LRRK2 gene or mutations in the SNCA or $G B A$ genes. The best outcome from DBS surgery appears to be in patients with $L R R K 2$ p.G2019S or PRKN mutations.

Acknowledgements Open access funding provided by University of Turku (UTU) including Turku University Central Hospital.

Author contributions (1) Research project: (A) Conception, (B) Organization, (C) Execution; (2) Statistical analysis: (A) Design, (B) Execution, (C) Review and critique; (3) Manuscript: (A) Writing of the first draft, (B) Review and critique. TK: 1A, 1B, 1C, 3A, 3B. JK: 1C, 3B. EP: 1C, 3B. MM: 1C, 3B. AA: 1C, 3B. VK: 1A, 1B, 1C, 3B.

Funding No targeted funding reported. Financial disclosures of all authors for the preceding 12 months. T.K.: Travel expenses from Abbott and Zambon. J.K.: Speaker's honoraria from Allergan and KRKA; travel expenses from Abbott and Bayer; and an advisory board 
membership for Allergan. E.P.: Speaker's honoraria from Abbott and Abbvie; travel expenses from Abbott, Abbvie, Boston Scientific and Medtronic; an advisory board membership for Abbvie; and consulting fees from NordicInfu Care and Zambon. M.H.M: Speaker's honoraria from Sanofi Genzyme Finland. A.A.: Honoraria from Sunovion, Lundbeck, Mundipharma, GE, UCB, Zambon, Medtronic, Ever Neuro Pharma and Movement Disorders Society; advisory board membership for AbbVie and Acadia; consulting fees from AbbVie, UCB, Zambon and Angelini; expert testimony and legal consultancy for Boehringer Ingelheim; stock ownership in PD Neurotechnology Limited; grant for Horizon2020 Project No 643706; and patent WO2015110261-A1 An in vitro method of diagnosing Parkinson's disease. V.K.: Speaker's honoraria from Orion Pharma, Teva, GE Healthcare, Abbvie and NordicInfu Care AB; travel expenses from NordicInfu Care AB; and an advisory board membership for Abbvie.

\section{Compliance with ethical standards}

Research involving human participants and animals This manuscript does not contain clinical studies or patient data apart from those identified through literature search.

Conflicts of interest The authors declare that they have no conflict of interest.

OpenAccess This article is distributed under the terms of the Creative Commons Attribution 4.0 International License (http://creativeco mmons.org/licenses/by/4.0/), which permits unrestricted use, distribution, and reproduction in any medium, provided you give appropriate credit to the original author(s) and the source, provide a link to the Creative Commons license, and indicate if changes were made.

\section{References}

1. Deuschl G, Schade-Brittinger C, Krack P et al (2006) A randomized trial of deep-brain stimulation for Parkinson's disease. N Engl J Med 355:896-908

2. Obeso JA, Olanow CW, Rodriguez-Oroz MC et al (2001) Deepbrain stimulation of the subthalamic nucleus or the pars interna of the globus pallidus in Parkinson's disease. N Engl J Med 345:956-963

3. Weaver FM, Follett K, Stern M et al (2009) Bilateral deep brain stimulation vs best medical therapy for patients with advanced Parkinson disease: a randomized controlled trial. JAMA 301:63-73

4. Antonini A, Moro E, Godeiro C, Reichmann H (2018) Medical and surgical management of advanced Parkinson's disease. Mov Disord 33:900-908

5. Schuepbach WM, Rau J, Knudsen K et al (2013) Neurostimulation for Parkinson's disease with early motor complications. N Engl J Med 368:610-622

6. Kasten M, Marras C, Klein C (2017) Nonmotor signs in genetic forms of Parkinson's disease. Int Rev Neurobiol 133:129-178

7. Deng H, Wang P, Jankovic J (2018) The genetics of Parkinson disease. Ageing Res Rev 42:72-85

8. Puschmann A (2013) Monogenic Parkinson's disease and parkinsonism: clinical phenotypes and frequencies of known mutations. Parkinsonism Relat Disord 19:407-415

9. Healy DG, Falchi M, O'Sullivan SS, et al (2008) Phenotype, genotype, and worldwide genetic penetrance of
LRRK2-associated Parkinson's disease: a case-control study. Lancet Neurol 7:583-590

10. Alcalay RN, Mirelman A, Saunders-Pullman R et al (2013) Parkinson disease phenotype in Ashkenazi Jews with and without LRRK2 G2019S mutations. Mov Disord 28:1966-1971

11. Romito LM, Contarino MF, Ghezzi D, Franzini A, Garavaglia B, Albanese A (2005) High frequency stimulation of the subthalamic nucleus is efficacious in Parkin disease. J Neurol 252:208-211

12. Masellis M, Collinson S, Freeman N et al (2016) Dopamine D2 receptor gene variants and response to rasagiline in early Parkinson's disease: a pharmacogenetic study. Brain 139:2050-2062

13. Moher D, Shamseer L, Clarke M et al (2015) Preferred reporting items for systematic review and meta-analysis protocols (PRISMA-P) 2015 statement. Syst Rev 4:1

14. Lythe V, Athauda D, Foley J et al (2017) GBA-associated Parkinson's disease: progression in a deep brain stimulation cohort. J Parkinsons Dis 7:635-644

15. Angeli A, Mencacci NE, Duran R et al (2013) Genotype and phenotype in Parkinson's disease: lessons in heterogeneity from deep brain stimulation. Mov Disord 28:1370-1375

16. Sayad M, Zouambia M, Chaouch M et al (2016) Greater improvement in LRRK2 G2019S patients undergoing Subthalamic Nucleus Deep Brain Stimulation compared to non-mutation carriers. BMC Neurosci 17:6

17. Greenbaum L, Israeli-Korn SD, Cohen OS et al (2013) The LRRK2 G2019S mutation status does not affect the outcome of subthalamic stimulation in patients with Parkinson's disease. Parkinsonism Relat Disord 19:1053-1056

18. Schüpbach M, Lohmann E, Anheim M et al (2007) Subthalamic nucleus stimulation is efficacious in patients with Parkinsonism and LRRK2 mutations. Mov Disord 22:119-122

19. Pal GD, Hall D, Ouyang B et al (2016) Genetic and clinical predictors of deep brain stimulation in young-onset Parkinson's disease. Mov Disord Clin Pract 3:465-471

20. Gómez-Esteban JC, Lezcano E, Zarranz JJ et al (2008) Outcome of bilateral deep brain subthalamic stimulation in patients carrying the R1441G mutation in the LRRK2 dardarin gene. Neurosurgery 62:857-862 (discussion 862-853)

21. Johansen KK, Jørgensen JV, White LR, Farrer MJ, Aasly JO (2011) Parkinson-related genetics in patients treated with deep brain stimulation. Acta Neurol Scand 123:201-206

22. Lesage S, Janin S, Lohmann E et al (2007) LRRK2 exon 41 mutations in sporadic Parkinson disease in Europeans. Arch Neurol 64:425-430

23. Gaig C, Ezquerra M, Marti MJ, Muñoz E, Valldeoriola F, Tolosa E (2006) LRRK2 mutations in Spanish patients with Parkinson disease: frequency, clinical features, and incomplete penetrance. Arch Neurol 63:377-382

24. Goldwurm S, Di Fonzo A, Simons EJ et al (2005) The G6055A (G2019S) mutation in LRRK2 is frequent in both early and late onset Parkinson's disease and originates from a common ancestor. J Med Genet 42:e65

25. Hatano T, Funayama M, Kubo SI et al (2014) Identification of a Japanese family with LRRK2 p.R1441G-related Parkinson's disease. Neurobiol Aging 35:2656.e2617-2656.e2656.e2623

26. Stefani A, Marzetti F, Pierantozzi M et al (2013) Successful subthalamic stimulation, but levodopa-induced dystonia, in a genetic Parkinson's disease. Neurol Sci 34:383-386

27. Puschmann A, Englund E, Ross OA et al (2012) First neuropathological description of a patient with Parkinson's disease and LRRK2 p.N1437H mutation. Parkinsonism Relat Disord 18:332-338

28. Perju-Dumbrava LD, McDonald M, Kneebone AC, Long R, Thyagarajan D (2012) Sustained response to deep brain stimulation in LRRK2 parkinsonism with the Y1699C mutation. J Parkinsons Dis 2:269-271 
29. Breit S, Wächter T, Schmid-Bielenberg D et al (2010) Effective long-term subthalamic stimulation in PARK8 positive Parkinson's disease. J Neurol 257:1205-1207

30. Aasly JO, Vilariño-Güell C, Dachsel JC et al (2010) Novel pathogenic LRRK2 p.Asn1437His substitution in familial Parkinson's disease. Mov Disord 25:2156-2163

31. Lohmann E, Welter ML, Fraix V et al (2008) Are parkin patients particularly suited for deep-brain stimulation? Mov Disord 23:740-743

32. Moro E, Volkmann J, König IR et al (2008) Bilateral subthalamic stimulation in Parkin and PINK1 parkinsonism. Neurology 70:1186-1191

33. Kim HJ, Yun JY, Kim YE et al (2014) Parkin mutation and deep brain stimulation outcome. J Clin Neurosci 21:107-110

34. Hassin-Baer S, Hattori N, Cohen OS, Massarwa M, Israeli-Korn SD, Inzelberg R (2011) Phenotype of the 202 adenine deletion in the parkin gene: 40 years of follow-up. Mov Disord 26:719-722

35. Thompson AJ, Scholz SW, Singleton AB, Hardwick A, McFarland NR, Okun MS (2013) Variability in clinical phenotypes of heterozygous and homozygous cases of Parkin-related Parkinson's disease. Int J Neurosci 123:847-849

36. Genç G, Apaydın H, Gündüz A et al (2016) Successful treatment of Juvenile parkinsonism with bilateral subthalamic deep brain stimulation in a 14-year-old patient with parkin gene mutation. Parkinsonism Relat Disord 24:137-138

37. Moll CK, Buhmann C, Gulberti A et al (2015) Synchronized cortico-subthalamic beta oscillations in Parkin-associated Parkinson's disease. Clin Neurophysiol 126:2241-2243

38. Nakahara K, Ueda M, Yamada K et al (2014) Juvenile-onset parkinsonism with digenic parkin and PINK1 mutations treated with subthalamic nucleus stimulation at 45 years after disease onset. J Neurol Sci 345:276-277

39. Lefaucheur R, Derrey S, Guyant-Maréchal L, Chastan N, Maltête D (2010) Whatever the disease duration, stimulation of the subthalamic nucleus improves Parkin disease. Parkinsonism Relat Disord 16:482-483

40. Wickremaratchi MM, Majounie E, Morris HR et al (2009) Parkinrelated disease clinically diagnosed as a pallido-pyramidal syndrome. Mov Disord 24:138-140

41. Lesage S, Magali P, Lohmann E et al (2007) Deletion of the parkin and PACRG gene promoter in early-onset parkinsonism. Hum Mutat 28:27-32

42. Capecci M, Passamonti L, Annesi F et al (2004) Chronic bilateral subthalamic deep brain stimulation in a patient with homozygous deletion in the parkin gene. Mov Disord 19:1450-1452

43. Khan NL, Graham E, Critchley P et al (2003) Parkin disease: a phenotypic study of a large case series. Brain 126:1279-1292

44. Weiss D, Brockmann K, Srulijes K et al (2012) Long-term followup of subthalamic nucleus stimulation in glucocerebrosidase-associated Parkinson's disease. J Neurol 259::1970-1972

45. Lesage S, Anheim M, Condroyer C et al (2011) Large-scale screening of the Gaucher's disease-related glucocerebrosidase gene in Europeans with Parkinson's disease. Hum Mol Genet 20:202-210

46. Martikainen MH, Päivärinta M, Hietala M, Kaasinen V (2015) Clinical and imaging findings in Parkinson disease associated with the A53E SNCA mutation. Neurol Genet 1:e27

47. Perandones C, Aráoz Olivos N, Raina GB et al (2015) Successful GPi stimulation in genetic Parkinson's disease caused by mosaicism of alpha-synuclein gene duplication: first description. J Neurol 262:222-223

48. Shimo Y, Natori S, Oyama G et al (2014) Subthalamic deep brain stimulation for a Parkinson's disease patient with duplication of SNCA. Neuromodulation 17:102-103

49. Antonini A, Pilleri M, Padoan A et al (2012) Successful subthalamic stimulation in genetic Parkinson's disease caused by duplication of the $\alpha$-synuclein gene. J Neurol 259:165-167
50. Ahn TB, Kim SY, Kim JY et al (2008) Alpha-synuclein gene duplication is present in sporadic Parkinson disease. Neurology 70:43-49

51. Fleury V, Wider C, Horvath J et al (2013) Successful long-term bilateral subthalamic nucleus deep brain stimulation in VPS35 Parkinson's disease. Parkinsonism Relat Disord 19:707-708

52. Chen YF, Chang YY, Lan MY, Chen PL, Lin CH (2017) Identification of VPS35 p.D620N mutation-related Parkinson's disease in a Taiwanese family with successful bilateral subthalamic nucleus deep brain stimulation: a case report and literature review. BMC Neurol 17:191

53. Kumar KR, Weissbach A, Heldmann M et al (2012) Frequency of the D620N mutation in VPS35 in Parkinson disease. Arch Neurol 69:1360-1364

54. Sheerin UM, Charlesworth G, Bras J et al (2012) Screening for VPS35 mutations in Parkinson's disease. Neurobiol Aging 33:838. e831-838.e835

55. Borellini L, Cogiamanian F, Carrabba G et al (2017) Globus pallidus internus deep brain stimulation in PINK-1 related Parkinson's disease: a case report. Parkinsonism Relat Disord 38:93-94

56. Valente EM, Salvi S, Ialongo T et al (2004) PINK1 mutations are associated with sporadic early-onset parkinsonism. Ann Neurol $56: 336-341$

57. Dufournet B, Nguyen K, Charles P et al (2017) Parkinson's disease associated with 22q11.2 deletion: clinical characteristics and response to treatment. Rev Neurol (Paris) 173:406-410

58. Stern MB, Marek KL, Friedman J et al (2004) Double-blind, randomized, controlled trial of rasagiline as monotherapy in early Parkinson's disease patients. Mov Disord 19:916-923

59. Shulman LM, Gruber-Baldini AL, Anderson KE, Fishman PS, Reich SG, Weiner WJ (2010) The clinically important difference on the unified Parkinson's disease rating scale. Arch Neurol 67:64-70

60. Rabie A, Verhagen Metman L, Fakhry M et al (2016) Improvement of advanced Parkinson's disease manifestations with deep brain stimulation of the subthalamic nucleus: a single institution experience. Brain Sci 6:58

61. Wells GA, Shea B, O'Connell D et al (2011) The NewcastleOttawa Scale (NOS) for assessing the quality of nonrandomized studies in meta-analysis. Available: http://www.ohri.ca/programs/ clinical_epidemiology/oxford.asp

62. Rizzone MG, Martone T, Balestrino R, Lopiano L (2018) Genetic background and outcome of Deep Brain Stimulation in Parkinson's disease. Parkinsonism Relat Disord. https://doi. org/10.1016/j.parkreldis.2018.08.006

63. Musacchio T, Rebenstorff M, Fluri F et al (2017) Subthalamic nucleus deep brain stimulation is neuroprotective in the A53T $\alpha$-synuclein Parkinson's disease rat model. Ann Neurol $81: 825-836$

64. Charles PD, Van Blercom N, Krack P et al (2002) Predictors of effective bilateral subthalamic nucleus stimulation for PD. Neurology 59:932-934

65. Okun MS, Rodriguez RL, Foote KD et al (2008) A case-based review of troubleshooting deep brain stimulator issues in movement and neuropsychiatric disorders. Parkinsonism Relat Disord 14:532-538

66. Wong JK, Cauraugh JH, Ho KWD et al (2018) STN vs. GPi deep brain stimulation for tremor suppression in Parkinson disease: a systematic review and meta-analysis. Parkinsonism Relat Disord. https://doi.org/10.1016/j.parkreldis.2018.08.017

67. Parihar R, Alterman R, Papavassiliou E, Tarsy D, Shih LC (2015) Comparison of VIM and STN DBS for Parkinsonian resting and postural/action tremor. Tremor Other Hyperkinet Mov (N Y) $5: 321$ 